\title{
Bicycle speed through different gears with drag
}

Ian Larson

University of South Florida

\author{
Advisors: \\ Arcadii Grinshpan, Mathematics and Statistics \\ Scott Campbell, Chemical and Biomedical Engineering \\ Problem Suggested By: Scott Campbell
}

Follow this and additional works at: https://digitalcommons.usf.edu/ujmm

Part of the Mathematics Commons

UJMM is an open access journal, free to authors and readers, and relies on your support: Donate Now

\section{Recommended Citation}

Larson, Ian (2019) "Bicycle speed through different gears with drag," Undergraduate Journal of Mathematical Modeling: One + Two: Vol. 10: Iss. 1, Article 4.

DOI: https://doi.org/10.5038/2326-3652.10.1.4909

Available at: https://digitalcommons.usf.edu/ujmm/vol10/iss1/4 


\title{
Bicycle speed through different gears with drag
}

\author{
Abstract \\ When riding a bicycle, the rider experiences two forces: the force of the road that acts upon the rear wheel \\ while pedaling, and an opposing force that exerts on the bicycle/cyclist, called aerodynamic drag force \\ (drag). When adjusting Newton's equation in the second law of motion, the instantaneous change in \\ velocity is equal to the object's net force divided by its mass. The corresponding differential equation has \\ not been solved analytically. With the bicycle starting at rest at $t=0$, we solved the equation numerically for \\ any time $t$ by using what is known as Euler's Method to plot the velocity as a function of time of the \\ bicycle through gear shifts. \\ Creative Commons License \\ (c) $\odot \Theta \Theta$
}

This work is licensed under a Creative Commons Attribution-Noncommercial-Share Alike 4.0 License. 


\section{PROBLEM STATEMENT}

The goal of this paper is to plot the velocity of a bike rider with drag force as a function of time given the needed parameters and the pedal force supplied by the rider. The velocity will start from zero - meaning the bike is initially at rest. Velocity will be plotted through three gear changes.

\section{MOTIVATION}

When an analytical solution to the original differential equation cannot be obtained, numerical analysis, in particular Euler's Method can be used. A bicycle shifting through gears with drag is a good illustration to show Euler's Method. With the bicycle starting at rest, its velocity can be plotted with respect to time.

\section{MATHEMATICAL DESCRIPTION AND SOLUTION APPROACH}

We remind the reader of Newton's second law of motion, since it will be used in the solution of the problem, and it will play a central role. The second law of motion states that the net external force of an object is proportional to its mass times its acceleration:

$$
\sum F=M a
$$

In our case, the only two forces we will be considering in (1) are $f_{\text {Road }}$ and $f_{\text {drag }}$, where $f_{\text {Road }}$ is the force of the road on the rear wheel while the cyclist pedals, and $f_{\text {drag }}$ is the drag force exerted on the cyclist. Rearranging Newton's equation we have:

$$
M a=f_{\text {Road }}-f_{\text {drag }}
$$


We will relate the force acting on the bicycle/cyclist system to its velocity by means of equation

(2). Since the derivative of velocity with respect to time is acceleration, we can substitute it in (2) to have the following equation:

$$
M \frac{d v}{d t}=f_{\text {Road }}-f_{d r a g}
$$

In (3), $t$ is time and $M$ is the combined mass of the cyclist and the cycle in $\mathrm{kg}$.

Equation (3) needs to be in terms of the known parameters. Consider the diagram below:

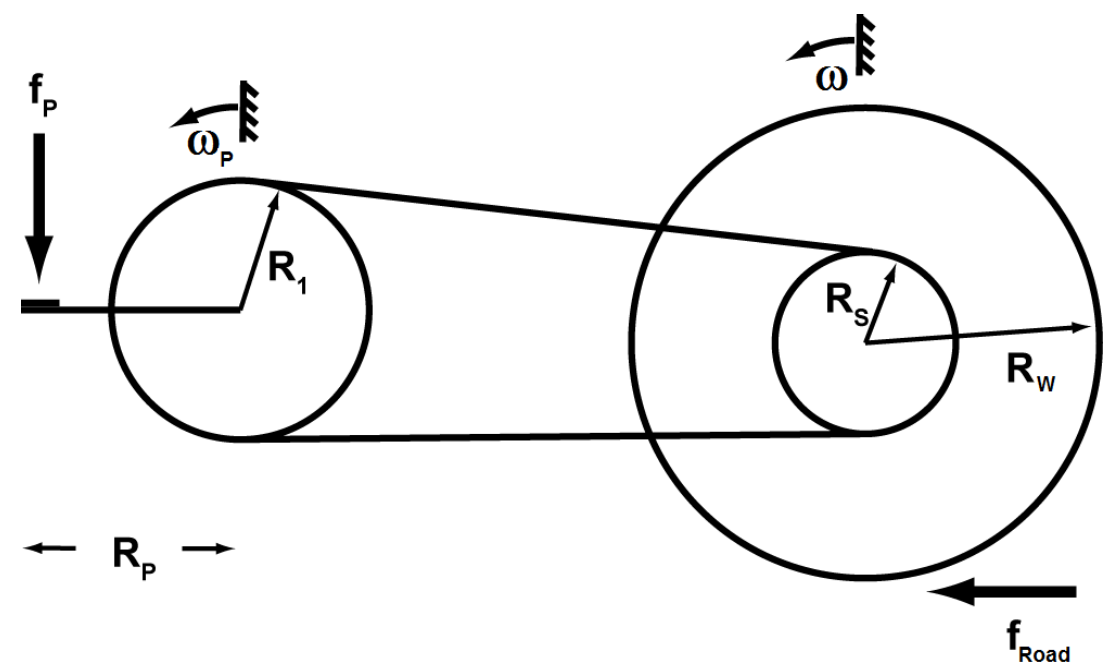

A torque balance around the front sprocket results in [5]:

$$
f_{p} R_{p}=R_{1} f_{c}
$$

In (4), $R_{1}$ is the front sprocket radius, $R_{p}$ is the pedal radius, $f_{p}$ is the force exerted by the cyclist in Newtons, and $f_{c}$ (not shown) is the force of the chain on the front sprocket. For the sake of simplicity moments of inertia of the front sprocket and rear wheel are ignored in this analysis. A torque balance in the rear wheel results in [5]:

$$
f_{c} R_{s}=R_{w} f_{\text {Road }}
$$

In (5), $R_{S}$ is the radius of the rear sprocket, which changes through shifts. $R_{w}$ is the radius of the rear wheel. Equation (4) and (5) imply that: 


$$
f_{\text {road }}=\frac{f_{p} R_{p} R_{S}}{R_{1} R_{w}}
$$

The drag force on the cyclist can be modeled by

$$
f_{\text {drag }}=\rho A C_{D} v^{2} / 2
$$

where $\rho$ is the density of air $\left(1.25 \mathrm{~kg} / \mathrm{m}^{3}\right.$ obtained from engineersedge.com [1]), $A$ is the area of the cyclist and bike normal to the direction of travel, $C_{D}$ is the drag coefficient and $v$ is the velocity of the bicycle [2, 3].

There is also a relationship between velocity $v$ of the bike and angular velocity $\omega$ of the rear wheel and between the angular velocity of the rear wheel and the angular velocity of the front sprocket $\omega_{p}$. These are:

$$
v=\omega R_{s}, \quad \omega R_{s}=\omega_{p} R_{1}
$$

We can substitute equations (4) - (8) into our differential equation (3) to obtain

$$
\frac{d v}{d t}=\frac{f_{p} R_{p} R_{s}}{M R_{1} R_{w}}-\frac{\rho A C_{D} v^{2}}{2 M}
$$

The velocity can now be calculated as a function of time through three gear changes, starting in first gear from rest at $t=0$. We need a reasonable angular velocity $\omega_{p}$ which will be used for each shift. Assume that the velocity $v$ will be continuous across the shift and that $\omega_{p}$ and $R_{s}$ will change instantaneously. Assume a constant pedal force $f_{p}$ is $100 \mathrm{~N}$ and specify the mass $M$, area $A$, and the required radii.

Now we apply Euler's method [4]. To this purpose, we recall the definition of derivative of a function $f(t)$ :

$$
\left(\frac{d f}{d t}\right)_{t=t_{0}}=f^{\prime}\left(t_{0}\right)=\lim _{\Delta t \rightarrow 0} \frac{f\left(t_{0}+\Delta t\right)-f\left(t_{0}\right)}{\Delta t}
$$

We arrange this equation as follows: $f\left(t_{1}\right) \approx f\left(t_{0}\right)+\Delta t \cdot f^{\prime}\left(t_{0}\right)$, 
where $f\left(t_{1}\right)$ is just $f\left(t_{0}+\Delta t\right)$. The equation above is only an approximation, but we know that as $\Delta t$ gets smaller, our approximation becomes more accurate. We can imagine the procedure for

finding $f\left(t_{2}\right) \approx f\left(t_{1}\right)+\Delta t \cdot f^{\prime}\left(t_{1}\right)$ where $t_{2}=t_{1}+\Delta t$ and so on until we have every numerical answer for all the times needed in the function.

In our problem, we know the value of $v\left(t_{0}\right)=0 \mathrm{~m} / \mathrm{s}$ and we also have our equation for $v^{\prime}$ (Equation 9). We will be starting at $t=0$ and use 0.1 seconds for $\Delta t$.

Finally, using Excel to our advantage, computations can be done by applying the procedure above.

\section{DISCUSSION}

For this trial we used our personal bicycle and measured all the needed values including our mass and the cross-sectional area of the bicycle and the rider himself. Starting in first gear from rest, a constant pedal force of one hundred Newtons we have shifted three times to end the trial in fourth gear. We have shifted at 15 radians/sec for all three shifts during a five second interval. Then the results on Excel before plotting Velocity vs. Time graph were calculated (see figure below): 


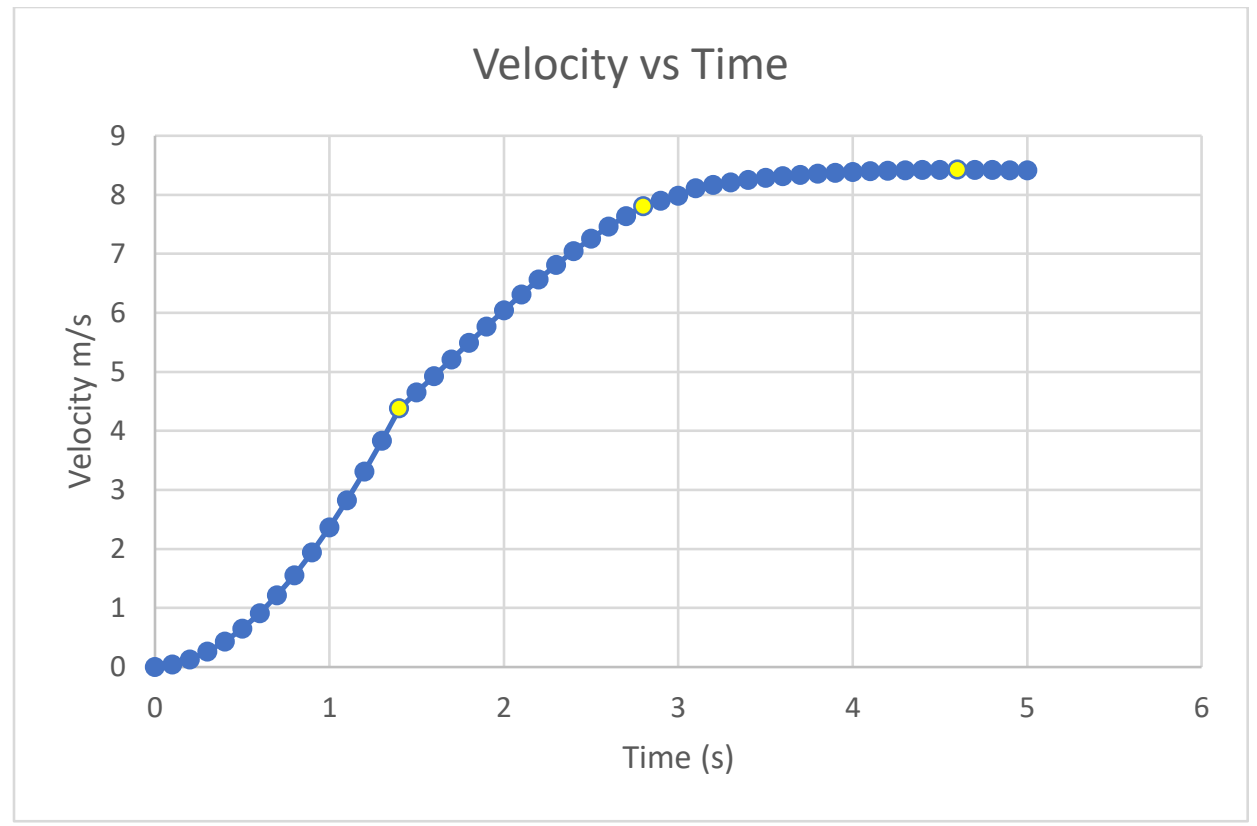

Each highlighted point represents a gear shift. Velocity did not change across the shift, but $\omega_{p}$ and $R_{S}$ changed instantaneously. Thus it is shown that a differential equation that does not have an analytical solution can be solved through numerical analysis.

\section{CONCLUSION AND RECOMMENDATIONS}

As one can see, Euler's method is a powerful approximation tool. We were able to numerically solve for velocity in all points of time needed to plot the bicycle speed through different gears with drag. With the results, ideas such as how much drag impacts a rider can be studied. It is also possible to apply similar methods to study optimization problems related to the speed of the bicycle in relation to changing radii of components, as well as how much speed is possible to maintain by decreasing the area normal to the drag force. 
Undergraduate Journal of M athematical M odeling: One + Two, Vol. 10, Iss. 1 [2019], Art. 4

NOMENCLATURE

\begin{tabular}{|c|c|c|c|}
\hline Symbol & Description & Unit & Value \\
\hline$f_{p}$ & Force of the pedal & Newtons & 100 \\
\hline$R_{p}$ & $\begin{array}{c}\text { Radius of the pedal } \\
\text { or crank }\end{array}$ & Meters & 0.15 \\
\hline$R_{S}$ & $\begin{array}{c}\text { Radius of } 1^{\text {st }} \text { gear } \\
\text { sprocket }\end{array}$ & Meters & 0.09 \\
\hline$R_{S_{2 n d}}$ & $\begin{array}{c}\text { Radius of second } \\
\text { gear }\end{array}$ & Meters & 0.05 \\
\hline$R_{S_{3 r d}}$ & Radius of $3^{\text {rd }}$ gear & Meters & 0.0461 \\
\hline$R_{S_{4 t h}}$ & Radius of $4^{\text {th }}$ gear & Meters & 0.0458 \\
\hline$M$ & $\begin{array}{c}\text { Mass of bike and } \\
\text { rider }\end{array}$ & Kilograms & 120 \\
\hline$R_{1}$ & $\begin{array}{l}\text { Radius of front } \\
\text { chainring }\end{array}$ & Meters & 0.07 \\
\hline$R_{w}$ & $\begin{array}{c}\text { Radius of the rear } \\
\text { wheel }\end{array}$ & Meters & 0.37 \\
\hline
\end{tabular}




\begin{tabular}{|c|c|c|c|}
\hline$\rho$ & $\begin{array}{c}\text { Density of air(at sea } \\
\text { level) }\end{array}$ & $\frac{\mathrm{kg}}{\mathrm{m}^{3}}$ & 1.25 \\
\hline$A$ & $\begin{array}{l}\text { Area of the rider and } \\
\text { bicycle against drag } \\
\text { force }\end{array}$ & $m^{2}$ & 0.75 \\
\hline$C_{d}$ & Drag coefficient & unitless & 0.88 \\
\hline$v$ & $\begin{array}{l}\text { Velocity of the } \\
\text { bicycle and the rider }\end{array}$ & $\mathrm{m} / \mathrm{s}$ & \\
\hline$\omega_{p}$ & $\begin{array}{c}\text { Rotational speed of } \\
\text { the pedal }\end{array}$ & Radians/sec & 15 \\
\hline$\omega$ & $\begin{array}{c}\text { Rotational speed of } \\
\text { the rear wheel }\end{array}$ & Radians/sec & Undesignated \\
\hline$f_{c}$ & Force of the chain & $\mathrm{m}$ & Undesignated \\
\hline
\end{tabular}




\section{REFERENCES}

[1] Density of air grabbed by Engineersedge.com:

LLC. (n.d.). Air Density and Specific Weight Table, Equations and Calculator. Retrieved

December 9, 2018, from https://www.engineersedge.com/calculators/air-density.html

[2] Drag coefficient value:

Lab, C. P. (n.d.). Cycling Aerodynamics \& CdA - A Primer. Retrieved December 9, 2018, from https://www.cyclingpowerlab.com/CyclingAerodynamics.aspx

[3] Vincent Chabroux, Caroline Barelle, and Daniel Favier. Aerodynamics of Cyclist Posture, Bicycle and Helmet Characteristics in Time Trial Stage. Journal of Applied Biomechanics, $2012,28,317-323$

[4] Larson, Ron, Robert Hostetler and Bruce Edwards. Calculus. 8th Edition. Boston, MA: Houghton Mifflin Company, 2005.

[5] Physics Stack Exchange. How bicycle gear works?

https://physics.stackexchange.com/questions/220992/how-bicycle-gear-works 